\title{
Martín-Cabello, Antonio; Anta Félez, Jose Luis; García-Manso, Almudena y Pérez Redondo, Rubén (2017): Turismo mochilero. Una aproximación desde la sociología y la antropología a una subcultura global. Oviedo: Septem Ediciones.
}

El concepto de mochilero ha estado tradicionalmente vinculado a un tipo de viajero excepcional, que goza de más libertad en la elección, diseño y estilo de viaje que el clásico turista, el cual realiza itinerarios estandarizados hacia lugares que están previamente preparados para él, sin poder salirse mucho del guión establecido, marcando de esta forma su experiencia viajera.

Desde la perspectiva de las Ciencias Sociales, el turismo es una actividad que no ha sido abordada con demasiado empeño aún siendo un fenómeno social complejo que genera multitud de situaciones, comportamientos y cifras dignas de ser estudiadas con rigor científico. En el caso particular del turismo mochilero la investigación es todavía más residual, con lo que existe un marcado déficit respecto al conocimiento de este segmento de la realidad viajera.

En este volumen los autores pretenden hacer un análisis del mochilero desde un doble enfoque, sociológico y antropológico, que suavice de alguna manera esa carencia de investigaciones al respecto. Por esa circunstancia los autores expresan el carácter ecléctico de esta obra para poder disponer de diferentes recursos metodológicos que les guíen hacia la construcción de un perfil inicial, aproximado, de este tipo de viajero, teniendo esta investigación la condición de obra abierta que sirva de motivación para otros estudios posteriores.

En la introducción del libro ya se nos advierte de la dificultad que entraña el concepto de mochilero al ser éste un término formalmente ligado al ámbito del turismo pero informalmente separado de él por los propios mochileros que rechazan con rotundidad ser catalogados como turistas. Sin embargo y a pesar de ese conflicto terminológico, el mochilero será analizado como un "subtipo de turista" ya que el tratamiento oficial de esta categoría de viajeros y la bibliografía existente al respecto los considera como una clase de turistas, con rasgos distintivos de éstos, pero turistas al fin y al cabo. Solventada esta salvedad en la parte introductoria, el libro se compone de otros cinco capítulos más unas conclusiones.

El segundo capítulo sirve como marco de referencia en donde se ubica el mochilerismo como una actividad surgida de la ancestral necesidad que tiene el humano de desplazarse a través del mundo por diferentes motivos, llevando adherido el ritual como un elemento motor de la causa viajera. Los diferentes peregrinajes como ritos de paso en la evolución cíclica de la vida se explican en este apartado con detalles de distintas civilizaciones que han experimentado estos tránsitos hacia otros lugares tanto geográficos como espirituales. Por lo tanto los viajes y más recientemente el turismo, en sus diferentes modalidades, son el precedente para el surgimiento posterior de la actividad mochilera que, según los autores, empieza a hacerse visible en los años cincuenta del siglo XX bajo la imagen del "vagabundo" y luego se desprenderán de esa imagen ligada a ciertos movimientos contraculturales y de protesta para constituirse en "mochileros", convirtiéndose así en una figura más loable socialmente.

En el tercer capítulo se hace una radiografía del mochilero. Al ser éste un colectivo poco convencional que auto-organiza sus viajes, la heterogeneidad es la norma y, sin embargo, no es impedimento para poder establecer unos rasgos comunes que los caractericen de forma general aun pudiendo hacerse una clasificación de los distintos subtipos de mochileros que puede haber. La prolongación del tiempo de viaje, que suele estar cercano al año, y la autogestión son dos de los rasgos más característicos de este grupo viajero que suele estar representado en mayor número por personas jóvenes, próximos a terminar estudios superiores o recién titulados, que proceden del mundo occidental, pertenecientes a un estrato social medioelevado y que utilizan para la realización de sus viajes múltiples medios de transporte, convencionales y no convencionales, por la enorme movilidad que tienen en los destinos, si bien el viaje principal suele ser realizado en transporte aéreo, lo cual se ha visto potenciado por el desarrollo de las compañías lowcost. Una de sus motivaciones viajeras más recurrentes sería la de exploración de nuevos lugares y culturas. El gasto realizado suele ser moderado en la rutina diaria pero superior al del turista de masas en el global de su periplo viajero. En este apartado, además de hacerse una clasificación de los distintos subtipos de mochileros que nos podemos encontrar, se aborda también el aspecto dinámico del mochilero, lo cual hace que evolucione y mute hacia otras variantes más modernas como por ejemplo la del flaspacker.

El capítulo siguiente está reservado para tratar los aspectos relacionados con la subcultura mochilera. En ese sentido los autores nos explican todo lo relativo a valores, conductas, símbolos, ritos, roles y demás elementos que lleva aparejado este estilo viajero para construir una identidad que les permite diferenciarse de los demás, a pesar de que a veces, esas pautas identitarias se quedan más en el plano de lo teórico y se alejan de la realidad. Para los mochileros, su rol es 
antagónico al del turista y se consideran como viajeros puros cuyo espíritu es el de descubrir mundos, explorarlos, vivirlos, sin la intercesión de terceros; sus valores fundamentales son los de la autenticidad, la libertad y la austeridad y en su experiencia viajera redunda una mayor interacción con las poblaciones locales de los lugares visitados que la que podrían tener los turistas convencionales; sin embargo, en el capítulo, los autores nos explicarán qué hay de cierto y qué de simulado en estas aseveraciones tan arraigadas en la mente de este colectivo. Alrededor del mochilero se construyen una serie de normas no escritas que guían su comportamiento y su actitud ante la vida, de tal manera que se suele decir que los integrantes de esta subcultura aparentan tener una manera homogénea de hacer las cosas. También se abordan aspectos relacionados con la cultura material del mochilero. En definitiva, en este apartado se da respuesta a este complejo aparataje cultural del mochilero descubriendo lo que hay de verdad y lo que hay de mitológico.

El quinto capítulo trata de relacionar el fenómeno de la globalización con el turismo mochilero. En ese sentido, si hay una actividad que pone de manifiesto las estrechas interconexiones que hoy se dan en el mundo, esa es la actividad viajera en sus diferentes versiones ya que pone en contacto a personas y culturas de muy diversa condición. Una vez abordadas las relaciones existentes entre globalización y viaje, los autores se centran en la descripción y el análisis de las múltiples habilidades y competencias que adquiere el mochilero en sus desplazamientos en la lógica de ese encuentro intercultural, haciéndose un planteamiento sobre si estas competencias y habilidades son similares a las que tiene otra de las subculturas globales; la de los expatriados corporativos. En este libro se constata que ambas subculturas son coincidentes en bastantes de las actividades que realizan y en los valores que asumen como consecuencia del sistema capitalista globalizado en el que se desenvuelven.

Finalmente, el sexto capítulo se centra en la exploración del fenómeno mochilero en España. Este tema ha sido poco investigado y los autores pretenden acercarnos a esta realidad para conocer si sus características y perfiles son comunes a la de los mochileros que recorren otros lugares de la geografía mundial. En este apartado se tratan los antecedentes del mochilerismo en España y se explica el por qué de las dificultades que tuvo para su despegue al surgir en un contexto de restricciones sociopolíticas derivadas de la dictadura franquista que controlaba todo, también la movilidad, y en ese sentido el turismo de masas era el modelo ideal al generar divisas y poder pasar por el control del régimen en detrimento de los modelos "aventureros" más autónomos y descontrolados. También se trata en este capítulo la construcción de las rutas mochileras que recorren nuestro país de norte a sur y de este a oeste, con mención añadida a los territorios insulares y a las vías verdes que son destacadas para este colectivo, además de analizar todo el complejo logístico y de infraestructuras que usan los mismos. Se termina este capítulo con una encuesta realizada por los autores con la que diseñan un perfil del turista mochilero por España, cerrándose el libro con las pertinentes conclusiones extraídas de todo el proceso de investigación.
Segundo Valmorisco Pizarro
Universidad Carlos III, España
svalmori@polsoc.uc3m.es

Recibida: 05-1-2017 Aceptada: 20-4-2017 